\title{
A Theory of Modular Production Networks
}

\author{
Ari Van Assche* \\ HEC Montréal
}

September 1, 2005

\begin{abstract}
In many globalized industries, the recent wave of vertical outsourcing seems to have co-evolved with increased horizontal consolidation in the component sector. To account for this phenomenon, I build an industry-equilibrium model in which the boundaries of the firm are endogenous in both the horizontal and vertical dimensions of production. This setup allows me to solve for the equilibrium conditions of four distinct production structures: (1) Vertical Integration; (2) Ideal Outsourcing under which intermediate good firms produce ideal components for final good firms; (3) Standardized Outsourcing under which input providers produce standardized components for multiple final good producers; and (4) Customized Outsourcing under which intermediate good firms produce customized components for multiple final good firms. The concept of product modularity is subsequently introduced into the model. The model demonstrates that product modularization can induce a co-evolution of vertical outsourcing and horizontal consolidation in the component sector through a de facto standardization of inputs and production processes.
\end{abstract}

JEL classification: F23, F12, L22

Keywords: outsourcing, product modularity, standardization.

\footnotetext{
${ }^{*}$ I would like to acknowledge comments I received from my dissertation committee, as well as from seminar participants at Bowdoin College, Franklin \& Marshall College, HEC Montréal, Texas Christian University, the University of California-Davis and the University of Hawaii at Manoa, and conference participants at the Mid-West International Economics Conference and the Southern Economics Association Conference. All remaining errors are my own. Correspondence: HEC Montréal, Department of International Business, 3000 Chemin de la Côte-Sainte-Catherine, Montréal (Québec), Canada H3T-2A7. E-mail: ari.van-assche@hec.ca.
} 


\section{Introduction}

An emerging international trade literature has focused on the determinants of international outsourcing by incorporating Grossman and Hart's (1986) and Hart and Moore's (1990) property rights theory of the firm into general-equilibrium trade models. ${ }^{1}$ The Grossman-Hart-Moore (GHM) framework states that - in an environment with incomplete contracts and relationship-specific investments - the residual rights of control over assets should be assigned to the party whose investment contributes most to the value of the relationship. If final good firms contribute more, vertical integration should occur; otherwise, outsourcing is preferable. In the trade literature, Grossman and Helpman (2002) have incorporatd elements of the GHM framework into a one-input general equilibrium model with monopolistic competition. By assuming that inputs must be fully tailored to final product specifications and that firms face incomplete contracts in arm's length relationships, they create a traditional hold-up problem under outsourcing. Firms weigh this holdup friction against the less efficient production of inputs under vertical integration. They use this setup to identify sectoral characteristics that lead to one or the other equilibrium structure. Antràs (2003) and Antràs and Helpman (2004) extend the Grossman and Helpman framework to a setting where both the input provider and the final good firm need to provide relationship-specific inputs. In accordance with GHM, they find that the relative intensity of these inputs turns out to be an important determinant of the choice between vertical integration and outsourcing. In particular, sectors that are relatively intensive in final-good components are predicted integrate, while sectors that are relatively intensive in intermediate-good components should outsource.

While these studies have laid important building blocks to explain the outsourcing phenomenon, the simplifying assumptions in these models that (1) inputs are completely specialized and of no use outside the existing relationship and (2) components can be sold to at most one final good firm, have led to an oversight of other outsourcing strategies that are actively adopted. ${ }^{2}$ Recent work on global value chain governance highlights the existence of multiple types of outsourcing relations with input providers depending on the degree of product and process standardization. Sturgeon and Lee (2001), for example, distinguish three types of input providers to whom lead firms outsource: (1) the "commodity supplier" provides generic products to the downstream firm;

\footnotetext{
${ }^{1}$ See Spencer (2005) for a survey of the international outsourcing literature.)

${ }^{2}$ Grossman and Helpman (2002) provide a model extension where assumption (1) is relaxed.
} 
(2) the "captive supplier" makes specialized products using machinery dedicated to the buyer's needs, and (3) the "turn-key supplier" uses flexible machinery to produce customized products for multiple buyers. They document that, in the electronics industry, brand-name electronics firms have primarily outsourced their manufacturing capacity to a handful of globally operating "turnkey" contract manufacturers. ${ }^{3}$ This has had important repercussions for the sector's industrial landscape, inducing the trend of vertical disintegration to co-evolve with an increased market concentration in its manufacturing segment. ${ }^{4}$ Similar trends have been found in other global industries such as semiconductors (Langlois and Steinmueller, 1999), telecommunications (Li and Whalley, 2002), and automobiles (Sturgeon and Florida, 2000). ${ }^{5}$ This co-evolution has far-reaching positive and normative implications. Positively, it provides further insights into the trends in international specialization. It suggests that the vertical outsourcing process does not necessarily lead to smaller firms and increased competition. Indeed, if it coincides with horizontal consolidation in some vertical layers of production, it can actually induce the emergence of large dominant contract manufacturing firms with monopoly power. Normatively, the co-evolution also has important implications on competition policy (Bresnahan, 1999; Economides, 1999) and industrial upgrading strategies of developing countries (Sturgeon and Lester, 2003).

Baldwin and Clark (2000), Langlois (2002) and Sturgeon (2002) have related the outsourcing of electronics production and the concomitant rise of the turn-key suppliers to the modularization of electronics products. With modular products, distinct breaks in the value chain tend to form at points where information regarding product specifications can be highly formalized and standardized. As a result, "turn-key suppliers" can take advantage of economies of scale and scope by apply the same generic production routines for multiple clients, without requiring personalized interactions with the buyers. As such, Sturgeon (2002) terms the co-evolution as the emergence of a new model of industrial organization, which he terms modular production networks.

\footnotetext{
${ }^{3}$ Estimates by Technology Forecasters, IDC, and Prudential Financial all pegged contract manufacturers' penetration of the total available market for circuit-board and product-level electronics manufacturing in 2000 at roughly $13 \%$ (Sturgeon, 2002).

${ }^{4}$ Electronic Trend Publications (2000) estimated that the top five contract manufacturers had captured $38 \%$ of the electronics contract manufacturing market by 1999, and expected this share to grow to $65 \%$ in 2003 primarily through mergers and acquisitions.

${ }^{5}$ To my knowledge, there have been no empirical studies that have systematically documented the rise and extent of manufacturing outsourcing. Nonetheless, semi-structured qualitative interviews conducted by researchers at MIT's Industrial Performance Center indicate that this reorganization has primarily occurred in complex assembly sectors such as electronics and motor vehicles.
} 
This paper sets out to explain the rise of modular production networks. For this purpose, I build an industry-equilibrium model in which the boundaries of the firm are endogenized in both the horizontal and vertical dimensions of production. Vertically, I assume that firms face a trade-off between double marginalization under outsourcing and extra fixed costs under vertical integration. Horizontally, I assume partial input specificity and economies of scale and scope in the intermediate good sector to endogenize the degree of market concentration in the intermediate good sector. These tradeoffs allow me to distinguish four production structures: (1) Vertical Integration under which final good firms produce their own specialized inputs; (2) Ideal Outsourcing under which "captured" intermediate good firms produce ideal components for final good firms; (3) Standardized Outsourcing under which "commodity" intermediate good firms produce standardized components for multiple final good producers; and (4) Customized Outsourcing under which "turnkey" intermediate good firms produce customized components for multiple final good firms. I incorporate the concept of modularity into the model by linking it to the economics literature concept of input specificity. The model demonstrates how the modularization of a product can induce a co-evolution of vertical outsourcing and horizontal consolidation in the intermediate good sector. If products are modular and if intermediate good firms can exploit economies of scale, then it can become profitable for a vertically integrated firm to outsource component production to an intermediate good firm that uses a generic production process (Customized Outsourcing) or produces standardized inputs (Standardized Outsourcing) to multiple final good producers. As such, this paper links the emergence of modular production networks to the de facto standardization of inputs and production processes that has been taking place in high technology industries such as electronics, telecommunications, semi-conductors and automobiles (Schilling and Steensma, 2001 and Sturgeon, 2002).

The paper is organized as follows. Section 2 defines modularity and links it to the concept of input specificity. Section 3 sets up the model by identifying the three basic cost trade-offs that determine the vertical and horizontal boundaries of the firm in industry equilibrium. In Section 4, the model is solved. Section 5 finally provides concluding remarks. 


\section{Product Modularity}

In the management literature, modularity defines the ease with which components can be separated and recombined without compromising system integrity (Baldwin and Clark, 2000; Garud and Kumaraswamy, 1995; Sanchez and Mahoney, 1996; Schilling, 2000; Ulrich, 1995). ${ }^{6}$ When a product is non-modular, components are specifically adjusted (i.e. tightly coupled) to each other to fully elicit the potential performance of the final product. As a result, any substitution of a component by another variety requires compensating changes to be made to the other components to uphold system integrity. Modular products, on the other hand, consist of loosely coupled components that interact with each other according to well-defined and codified architectural standards. As long as components are compatible to the architectural standards, they thus can be mixed and matched without having to make compensating changes to the other components. Modularizing a product thus can lead to important strategic advantages when it enables a firm to correspond more readily to customer heterogeneity by creating product variations through the mixing and matching of new or existing modular components.

This paper argues that the notion of product modularity can be related to the economics literature's concept of input specificity. ${ }^{7}$ In a recent paper, Grossman and Helpman (2002) introduced input specificity in their model by associating each final product with an ideal input. If the ideal input is adopted, then the final good firm can use the input for final good production without a need for spending additional customization costs. However, if a more standardized (i.e. non-ideal) input is adopted, then additional resources need to be spent to customize the input to the final good requirements. The concept of modularity can be linked to input specificity by allowing the amount of customization costs to vary across products. If a product is non-modular, many additional resources need to be spent to customize standardized inputs to the final good requirements. If a product is modular, few resources need to be spent to customize standardized inputs. We will use this link with input specificity to introduce product modularity in the model below.

\footnotetext{
${ }^{6} \mathrm{PCs}$ and cell phones are good examples of modular products. They are essentially a limited number of standard parts or modules (e.g., resistors, capacitors, and memory chips), which get mounted onto printed circuit boards in different combinations. In assembling these products, contract manufacturing firms can customize products for heterogeneous end users at a relatively low cost.

${ }^{7}$ Input specificity is a type of asset specificity.
} 


\section{Model Setup}

Consider an industry that produces differentiated consumer goods. For each variety, the production structure consists of two vertical layers of production, an intermediate good layer $z$ and a final good layer $x$. To produce intermediate goods $z$, a unit of labor is required at wage $w$. I normalize wage $w$ to 1 . To produce a final good, one unit of intermediate good is required.

In the intermediate goods sector $z$, identical firms face increasing returns to scale and produce differentiated inputs in a contestable market setting. In the final goods sector $x$, identical firms produce differentiated final goods and compete in a Dixit-Stiglitz monopolistic competition market. Final good firms buy the intermediate goods on the market and cannot affect the market price through bargaining. As will be derived below, this setup of successive stages of production with imperfect competition creates a cost trade-off that endogenizes the vertical boundaries of the firm in industry equilibrium. If final good firms outsource, they face a high marginal cost due to "double marginalization" (Spengler, 1950) but do not need to pay the fixed cost of setting up a subsidiary. If the final good firms decide to set up a subsidiary, they internalize the double marginalization distortion, but need to spend the additional fixed cost to set up the subsidiary. Similar to Abiru et al. (1998) and Feenstra et al. (2003), this trade-off will determine whether firms will be vertically integrated or will outsource in industry equilibrium.

To incorporate input specificity into the model, I follow Grossman and Helpman (2002) by associating each final product with an ideal component. If a component is ideal, then the intermediate good can be used in final good production without a need for spending additional customization costs. However, if the intermediate good is not fully specialized (i.e., not fully compatible to the architectural standards), then additional units of labor need to be spent to customize the component to the final good requirements. ${ }^{8}$ To operationalize input specificity in the model, I assume that intermediate and final goods are located on two separate concentric circles. All final goods are symmetrically and uniformly distributed along the circumference of a unit circle. All intermediate goods are arrayed along the circumference of a concentric circle of length $\gamma$, with $\gamma$ ranging from 0 to $\infty$. An intermediate good is assumed to be ideal for a final good if it lies on the same ray from the origin as the final good. If it does not lie on the same ray, then customization cost $\delta$

\footnotetext{
${ }^{8}$ For simplicity, I choose to abstract from additional fixed customization costs that might occur. As such, spending of additional resources for customization is equivalent to a loss in productivity.
} 
arises, where $\delta$ equals the intermediate good circle's arc distance between the intermediary good and the ideal intermediary good. An example is given in Figure 1. Four final good firms $x_{1}$ to $x_{4}$ are uniformly distributed along the unit length final good circle. The ideal intermediate good for $x_{1}$ is $z_{1}$, the ideal intermediate good for $x_{2}$ is $z_{2}$ and so on. Suppose that final good firm $x_{1}$ decides to use the non-ideal intermediate good $z_{s 1}$ to produce the final good. In this case, customization $\operatorname{cost} \delta$ arises, where $\delta$ equals the arc distance between $z_{1}$ and $z_{s 1}$.

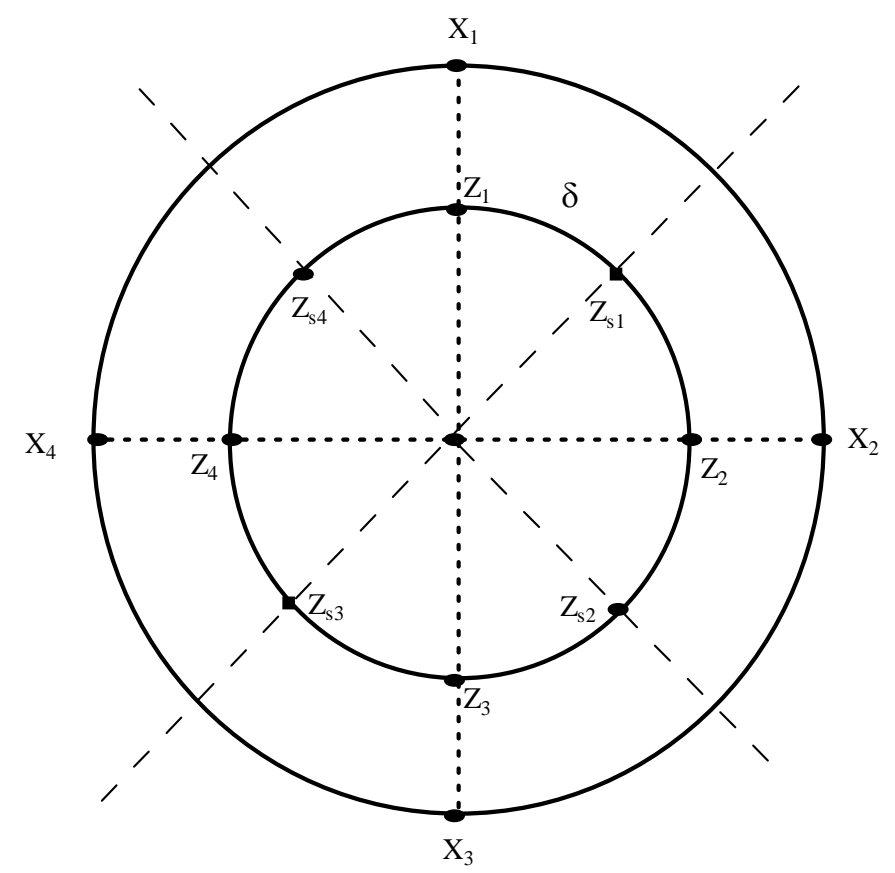

Figure 1: Locations of Final and Intermediate Good Suppliers

The combination of input specificity and increasing returns to scale in the intermediate good sector creates a second cost trade-off that endogenizes the degree of market concentration in the intermediate good sector under outsourcing. In particular, it determines whether "captured" intermediate good firms sell specialized inputs to one final good firm or whether "commodity" or "turn-key" suppliers consolidate their market share by providing standardized or customized inputs to two final good firms. ${ }^{9}$ If intermediate good firms all produce ideal components, then no customization costs occur, but the intermediate good firms face a relatively high average cost since they only sell to one final good firm. In figure 1, this would correspond to a situation where $z_{1}$ is

\footnotetext{
${ }^{9}$ For symmetry purposes, I assume that intermediate good firms can sell components to at most two final good firms.
} 
produced for $x_{1}, z_{2}$ is produced for $x_{2}$ and so on. If half the number of intermediate good firms each produce standardized components or uses standardized production processes for two final good firms, intermediate good firms are able to move down their average cost curves, but customization costs occur. In this case, the location of the intermediate good will be centered between two ideal inputs for two final good firms and the equilibrium customization $\operatorname{cost} \delta=\frac{\gamma}{2 n}$, with $n$ being the number of final good firms. In figure 1, this would correspond to one of the following two situations: $z_{s 1}$ is produced for $x_{1}$ and $x_{2}$ and $z_{s 3}$ is produced for $x_{3}$ and $x_{4}$; or $z_{s 2}$ is produced for $x_{2}$ and $x_{3}$ and $z_{s 4}$ is produced for $x_{1}$ and $x_{4} \cdot{ }^{10}$ Note that under this scenario the number of firms in the intermediate good sector is half the number of firms in the final good sector. As a result, the degree of market concentration in the intermediate good sector is higher. To summarize the equilibrium customization costs:

$$
\delta=\left\{\begin{array}{ccc}
0 & \text { if intermediate good firms produce ideal components } \\
\frac{\gamma}{2 n} & \text { if intermediate good firms produce standardized or customized components }
\end{array}\right.
$$

The condition above implies that the amount of customization costs when standardized components or production processes are used depends on two factors: the equilibrium number of final good firms $n$ and the length of the intermediate good circle $\gamma$. An increase in $n$ reduces the equilibrium customization cost of providing standardized components because the ideal inputs are located closer to one another on the intermediate good circle. An increase in $\gamma$ increases the equilibrium customization cost because it increases the length of the intermediate good circle and thus makes all component varieties further substitutes to one another. ${ }^{11}$ This characteristic is similar to an decrease in product modularity and for this reason I put forward the following proposition:

Proposition 1 The degree of product modularity can be proxied by $\frac{1}{\gamma}$.

A final question that arises in this setup is which firm faces the burden of customization. In a model without economies of scope, the burden of customization unambiguously falls on the final good firms (Van Assche, 2003). When intermediate good firms face economies of scope, however, the burden

\footnotetext{
${ }^{10} \mathrm{~A}$ situation where $n$ intermediate good firms all are located between two ideal components cannot constitute an equilibrium because intermediate good firms would have the incentive to start producing ideal components to get rid of the required customization costs.

${ }^{11}$ Take figure 1 as an example. Suppose the intermediate good circle becomes smaller due to an increase in $\gamma$. In that case, the customization cost of using $z_{3}$ in the production of $x_{1}$ and $x_{2}$ reduces.
} 
of customization becomes endogenous. In the next section, I will introduce economies of scope by assuming that intermediate good firms use flexible manufacturing technologies to manufacture differentiated components (Eaton and Schmitt, 1994). ${ }^{12}$ The essence of this technology is that intermediate good firms have the ability to modify their base product to any other variant by incurring the customization costs themselves. As we shall see, the burden of customization crucially depends on the intermediate and final good firms' relative efficiency of customizing components.

As is demonstrated in Figure 2, the three cost-tradeoffs described above allow the distinction of four production structure regimes. In Figure 2, the top horizontal line represents the intermediate good circle, while the bottom line corresponds to the final good circle. Blocks stand for the activities that occur within the boundaries of the firm and circles represent product varieties. Arrows finally correspond to the direction of activities. Under Vertical Integration (VI), final good firms set up subsidiaries and produce specialized intermediate good for themselves only. As a result, both the upstream and downstream activities are represented within the final good block. Under Ideal Outsourcing $(I O)$, external intermediate good firms produce ideal components for one final good firm. Under Standardized Outsourcing $(S O)$, external intermediate good firms produce standardized components for two final good producers and the burden of customization falls on the final good firms. Under Customized Outsourcing $(C O)$, intermediate good firms produce a base component for two final good firms and face the burden of customization themselves. The equilibrium production structure is determined by a two-step procedure. In step one, intermediate and final good firms choose from the four production structures to produce consumer goods. In step two, the firms select the profit maximizing price and quantity given the production regime chosen. The problem is solved through backward induction. ${ }^{13}$

\section{The Model}

Global consumers spend a constant fraction $\beta$ of their income $E$ on output from the industry. They view the varieties by the industry as symmetrically differentiated and perceive a constant elasticity of substitution $\sigma$ between every pair of goods. Each consumer maximizes a subutility function of

\footnotetext{
${ }^{12}$ The U.S. Office of Technology Assessment defines flexible manufacturing systems as: A production unit capable of producing a range of discrete products with a minimum of manual intervention.

${ }^{13}$ The full game tree of this model is described in Van Assche (2003).
} 


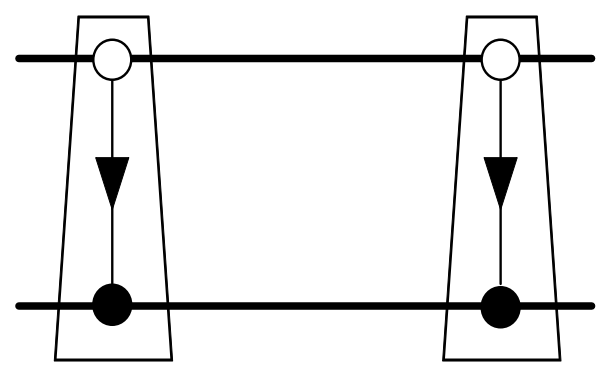

Vertical Integration

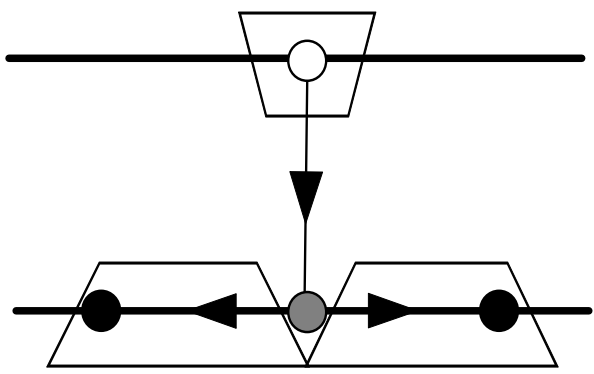

Standardized Outsourcing

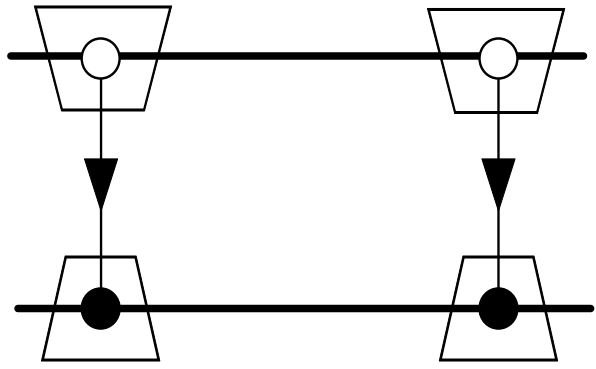

Ideal Outsourcing

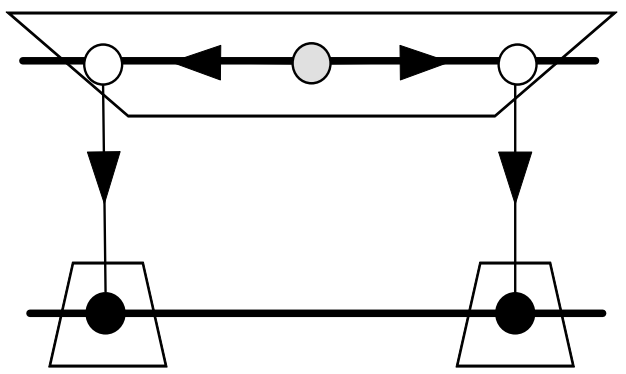

Customized Outsourcing

Figure 2: Four Production Structures

the following form:

$$
U=\int_{0}^{n} x(i)^{\frac{\sigma-1}{\sigma}} d i, \quad 0<\beta<1
$$

where $x(i)$ is consumption of product $i$ and $n$ is the measure of the number of final products available on the market. These preferences yield the following demand functions for each variety $i$ :

$$
x(i)=A p_{x}(i)^{-\sigma}
$$

where

$$
A \equiv \frac{\beta E}{\int p_{x}(i)^{1-\sigma} d i}
$$




\subsection{Vertical Integration}

In stage 2, firms maximize their profits given the production structure chosen in stage 1. I start off by assuming that all identical firms are vertically integrated $(V I)$. In that case, each final good producer chooses to produce the intermediate good $z$ himself. He naturally chooses to produce the ideal component because he is only allowed to sell components to himself and does not want to bear self-imposed customization costs. The final goods producer thus faces the following profit function:

$$
\pi_{x}^{V I}=\left(p_{x}(X)-1\right) x-F-G_{x}
$$

where the marginal cost of production is normalized wages $w$ induced during intermediate good production. The fixed cost of $V I$ production includes the fixed cost of setting up a final good firm $F$ and the fixed cost of setting up a subsidiary for component production $G_{x}$. Both fixed costs are assumed to be paid in normalized wages. The corresponding first-order condition of optimization provides the standard Dixit-Stiglitz result that the price-marginal-cost mark-up depends only on the elasticity of substitution $\sigma$ :

$$
\tilde{p}_{x}^{V I}=\frac{\sigma}{\sigma-1}
$$

By plugging the pricing equation (5) and the demand function (2) into the profit function (4), the expected profit function of a vertically integrated firm is:

$$
\tilde{\pi}_{x}^{V I}=A^{V I} \sigma^{-\sigma}(\sigma-1)^{\sigma-1}-F-G_{x}
$$

Since all firms are identical, (3) reduces to $A=\frac{\beta E}{n p_{x}}$. Imposing the zero profit condition on (6), and combining it with (3) and (5) allows the determination of the equilibrium number of firms:

$$
\tilde{n}=\frac{\beta E}{\sigma\left(F+G_{x}\right)}
$$

This leads to the standard Dixit-Stiglitz result that the number of firms is increasing in industry demand $\beta E$, and decreasing in the elasticity of substitution $\sigma$ and the fixed cost of vertical integration $F+G_{x}$. 


\subsection{Outsourcing}

Under outsourcing, a final good firm relies on an external intermediate good firm to produce its inputs. In that case, profits need to be maximized for both the intermediate good firms and the final good firms. I start with the optimization decision for the final good producers. The final good firm under outsourcing buys its intermediate goods from an external provider and potentially spends

additional resources to customize it. I assume that the final good producers cannot manipulate the intermediate good price through bargaining. He thus faces the following profit maximization problem:

$$
\pi_{x}^{k}=\left(p_{x}^{k}(X)-r \delta_{x}^{k}-p_{z}^{k}(Z)\right) x-F
$$

where $k$ represents the three types of outsourcing, $p_{z}$ is the price of the purchased intermediate good, $\delta_{x}$ is the customization costs that the final good firm faces, and $r$ is a scale parameter that captures the final good firm's relative inefficiency in customizing the intermediate goods. Note that $\delta_{x}$ will only be positive under Standardized Outsourcing, since this is the only configuration where final good firms face the cost of customizing the input themselves.

The final good producer's profit function (8) under outsourcing differs from the profit function under vertical integration (4) in two important ways. On the one hand, the final good producer now faces a lower fixed cost than under vertical integration as he does not incur the fixed cost $G_{x}$ of setting up a subsidiary. On the other hand, the final good producer now faces a higher marginal cost with $p_{z}$ than under vertical integration as he has to pay an extra markup and potential customization $\operatorname{costs} \delta_{x}$ to purchase the intermediate good. As mentioned above, this double marginalization tradeoff determines the vertical boundaries of the firm in this model.

The rest of the analysis is similar to the analysis of vertical integration in 4.1. If I set the marginal revenue equal to the marginal cost and make use of Dixit-Stiglitz preferences:

$$
\tilde{p}_{x}^{k}=\left(\frac{\sigma}{\sigma-1}\right)\left(r \delta_{x}^{k}+p_{z}^{k}\right)
$$

By plugging the pricing equation (9) and the demand function (2) into the profit function (8), the expected profit of the final good firm is:

$$
\tilde{\pi}_{x}^{k}=A^{k} \sigma^{-\sigma}(\sigma-1)^{\sigma-1}\left(r \delta_{x}^{k}+p_{z}^{k}\right)^{1-\sigma}-F
$$


The Dixit-Stiglitz zero-profit condition together with (3) and (9) allows the determination of the equilibrium number of final good firms under the three types of outsourcing:

$$
\tilde{n}^{k}=\frac{\beta E}{\sigma F}
$$

The determination of the equilibrium number of firms in (11) allows me to establish the equilibrium customization cost under Standardized or Customized Outsourcing:

$$
\tilde{\delta}=\frac{\gamma}{2 \tilde{n}}=\frac{\gamma \sigma F}{2 \beta E}
$$

Equation (12) indicates that the customization cost $\tilde{\delta}$ is positively related to the degree of final good competition $\sigma$ and to the final good firms' fixed set up cost $F$. It is negatively related to the degree of product modularity $\frac{1}{\gamma}$, and industry demand $\beta E$. Finally, combining (2) and (9) allows the determination of each firm's final good output under outsourcing:

$$
x=\frac{F(\sigma-1)}{p_{z}^{k}+r \delta_{x}^{k}}
$$

As in Eaton and Schmitt (1994), I assume that intermediate good firms use a flexible manufacturing technology in production which exhibit both economies of scale and economies of scope. They face a fixed cost $G_{z}$ for setting up their firm and developing a base product, a constant marginal cost normalized to 1 to produce a unit of a base product and, potentially, a marginal $\operatorname{cost} \delta_{z}$ to customize a product for a final good producer. An intermediate good firm thus faces the following profit function under outsourcing:

$$
\pi_{z}^{k}=\left(p_{z}^{k}(Z)-\left(1+\delta_{z}^{k}\right)\right) z-G_{z}
$$

From Figure 2, it is clear that the customization $\operatorname{cost} \delta_{z}$ depends on the outsourcing strategy adopted. under Ideal Outsourcing $\delta_{z}^{I O}=0$ because the "captive" intermediate good firms produce ideal components for final good firms. Under Standardized Outsourcing, $\delta_{z}^{S O}=0$ because the burden of customizing the standardized component falls on the final good firms. Under Customized Outsourcing $(C O), \delta_{z}^{C O}=\frac{\gamma \sigma F}{2 \beta E}$ because the "turn-key" intermediate good firms bear the burden of 
customizing the standardized components.

To solve for the intermediate good firm's profit maximization condition, I will rely on the assumption of market contestability and the fact that for each unit of final good output exactly one unit of intermediate good output is required. Since under Ideal Outsourcing each intermediate good producer produces specialized inputs for one final good producer, intermediate good output per firm is identical to (13). In other words, $z^{I O}=\frac{F(\sigma-1)}{p_{z}^{I O}}$. Under Standardized and Customized Outsourcing, on the other hand, each intermediate good firm is the sole provider for two final good firms. As a result, $z^{C O}=2 \frac{F(\sigma-1)}{p_{z}^{C O}}$ and $z^{S O}=2 \frac{F(\sigma-1)}{p_{z}^{S O}+r \frac{\gamma \sigma F}{2 \beta E}}$. By combining the intermediate good firm's output level with the zero profit condition of contestable markets, intermediate good prices under the three types of outsourcing are:

$$
\begin{gathered}
p_{z}^{I O}=\frac{F(\sigma-1)}{F(\sigma-1)-G_{z}} \\
p_{z}^{C O}=\frac{F(\sigma-1)(\gamma \sigma F+2 \beta E)}{\left(2 F(\sigma-1)-G_{z}\right) \beta E} \\
p_{z}^{S O}=\frac{F(\sigma-1)\left(r \gamma \sigma F G_{z}+2 \beta E\right)}{\left(2 F(\sigma-1)-G_{z}\right) \beta E}
\end{gathered}
$$

By incorporating the intermediate good prices into (10), we are able to determine the final good firm's profit function under the three types of outsourcing:

$$
\begin{gathered}
\pi_{x}^{I O}=A^{I O} \sigma^{-\sigma}\left(\frac{F(\sigma-1)-G_{z}}{F}\right)^{\sigma-1}-F \\
\pi_{x}^{C O}=A^{C O} \sigma^{-\sigma}\left(\frac{\left(2 F(\sigma-1)-G_{z}\right) \beta E}{F(\gamma \sigma F+2 \beta E)}\right)^{\sigma-1}-F \\
\pi_{x}^{S O}=A^{S O} \sigma^{-\sigma}\left(\frac{\left(2 F(\sigma-1)-G_{z}\right) \beta E}{F(r \gamma \sigma F+2 \beta E)}\right)^{\sigma-1}-F
\end{gathered}
$$

\subsection{Industry Equilibrium Determination}

In section 4.1 and 4.2, I have solved for the second stage of the model by deriving the profit maximizing price and output under vertical integration and the three types of outsourcing. In this section, I solve the first stage of the model by solving for the equilibrium production structure.

I start off by focusing on the condition under which Customized Outsourcing is preferred to 
Standardized Outsourcing. This will be the case if a Standardized Outsourcing firm that enters a Customized Outsourcing market makes negative profits. Suppose that it enters the market. In that case, it will face the same equilibrium demand $A^{C O}$ as the other Customized Outsourcing firms, but will have a different profit function (20). $A^{C O}$ can be derived by inserting (9) and (11) into $(3)$ :

$$
\tilde{A}^{C O}=(\sigma F)^{\sigma}\left(\frac{\gamma \sigma F+2 \beta E}{\left(2 F(\sigma-1)-G_{z}\right) \beta E}\right)^{\sigma-1}
$$

By inserting (21) into (20), and imposing negative operating profits, it can be determined that Customized Outsourcing will be chosen over Standardized Outsourcing if:

$$
r \geq 1
$$

The condition under which Standardized Outsourcing is preferred to Customized Outsourcing can be derived in a similar fashion. Suppose a Customized Outsourcing firm enters a prevalent Standardized Outsourcing market. In that case, it will face the same equilibrium demand $A_{S O}$, where:

$$
\tilde{A}^{S O}=(\sigma F)^{\sigma}\left(\frac{r \gamma \sigma F+2 \beta E}{\left(2 F(\sigma-1)-G_{z}\right) \beta E}\right)^{\sigma-1}
$$

By inserting (23) into (19), and imposing negative operating profits, it can be determined that Standardized Outsourcing will be chosen over Customized Outsourcing if:

$$
r \leq 1
$$

Equations (22) and (24) demonstrate that firms with a Customized and Standardized Outsourcing configuration cannot coexist, except in a knife-edge case. If intermediate good firms are more efficient in customizing the inputs, then Customized Outsourcing is preferred. Otherwise, Standardized Outsourcing is preferred.

By systematically evaluating the conditions under which nor a Vertically Integrated firm nor an Ideal Outsourcing firm are willing to enter a Standardized and Customized Outsourcing equilibrium, we can derive the following theorem: 
Theorem 1 If the following two inequalities hold

$$
\begin{gathered}
\left(\frac{2 F(\sigma-1)-G_{z}}{F(\sigma-1)} * \frac{\beta E}{2 \beta E+\min (1, r) \gamma \sigma F}\right)^{\sigma-1}\left(\frac{F+G_{x}}{F}\right) \geq 1 \\
\frac{\beta E G_{z}}{\min (1, r) \gamma \sigma F\left(F(\sigma-1)-G_{z}\right)} \geq 1 \\
\operatorname{then}\left\{\begin{array}{l}
\text { Customized Outsourcing is the equilibrium production structure if } r \geq 1 \\
\text { Standardized Outsourcing is the equilibrium production structure if } r \leq 1
\end{array}\right.
\end{gathered}
$$

The inequalities in Theorem 1 can be used to analyze the impact of various market and product determinants on the equilibrium production structure. Consider first the effects of raising product modularity through a decrease in $\gamma$. Since this reduces the equilibrium customization cost $\delta$, this induces Customized Outsourcing if $r \geq 1$ and Standardized Outsourcing if $r \leq 1$.

Next, consider the effects of an increase in industry demand $\beta E$. A special artifact of the DixitStiglitz monopolistic competition model is that a rise in industry demand only leads to an increase in the number of firms while leaving firm scale unchanged. Since an expansion of the number of firms in our model reduces the equilibrium customization $\operatorname{costs} \delta$, an increase in industry demand $\beta E$ thus induces Customized Outsourcing if $r \geq 1$ and Standardized Outsourcing if $r \leq 1$. Note that our model thus provides a theoretical legitimation of Stigler's (1951) hypothesis that vertical disintegration should be the typical development in growing industries.

The impact of an increase in the elasticity of substitution $\sigma$ on the prevalence of Customized or Standardized Outsourcing is ambiguous. On the one hand, it increases final good output, thus allowing the intermediate good firm to move down its average cost curve faster under Standardized and Customized Outsourcing than under other production configurations. On the other hand, it results in an increase in equilibrium customization $\operatorname{cost} \delta$ through an increase in the number of firms. Simulations show that Standardized and Customized Outsourcing can only be an equilibrium at intermediate levels of $\sigma$ : according to (25), vertical integration dominates if $\sigma$ is sufficiently low and high; According to (26), Ideal Outsourcing dominates at high levels of $\sigma$.

Similarly, the impact of an increase in firm-level scale economies $F$ has an ambiguous effect. Like an increase in $\sigma$, it on the one hand increases final good output, thus allowing intermediate good firms to move down their average cost curves faster under Standardized and Customized 
Outsourcing. On the other hand, it reduces the number of firms, thus increasing the equilibrium customization costs. An increase in $F$ will induce Standardized or Customized Outsourcing if $F$, $G_{x}$ and $G_{z}$ are sufficiently high.

Finally, it needs to be noted that intermediate good-level fixed $\operatorname{costs} G_{z}$ needs to be sufficiently high for a Standardized or Customized Outsourcing equilibrium to exist. The relative fixed cost $G_{z} / G_{x}$, however, needs to remain low.

To be complete, we need to determine under which conditions Ideal Outsourcing is a stable equilibrium. Suppose that a group of firms with another production structure attempts to enter a market that has pervasive Ideal Outsourcing. In that case, the final good firm faces the same demand $A^{I O}$ as the other Ideal Outsourcing firms with:

$$
\tilde{A}^{I O}=(\sigma F)^{\sigma}\left(F(\sigma-1)-G_{z}\right)^{1-\sigma}
$$

By systematically evaluating the conditions under which firms of no other production configuration are willing to enter an Ideal Outsourcing equilibrium, we can derive Theorem 2:

Theorem 2 Ideal Outsourcing will act as a stable equilibrium if the following two conditions hold:

$$
\begin{aligned}
\left(\frac{F(\sigma-1)}{F(\sigma-1)-G_{z}}\right)^{\sigma-1} \frac{F}{F+G_{x}} & \leq 1 \\
\frac{\beta E G_{z}}{\min (r, 1) \gamma \sigma F\left(F(\sigma-1)-G_{z}\right)} & \leq 1
\end{aligned}
$$

Theorem 2 indicates that, all else equal, Ideal Outsourcing is most likely to occur in industries with non-modular products, with low economies of scale in the intermediate good sector and high economies of scale in the final good sector.

By systematically evaluating the conditions under which firms of no other production configuration are willing to enter a Vertical Integration equilibrium, and comparing them to Theorem 1 and Theorem 2, it is obvious that no two production structures can co-exist except in a knife-edge case. This leads to the following Theorem:

Theorem 3 Generically, no industry has a coexistence of multiple production structures. 


\section{Conclusion}

This paper has developed a theoretical framework to analyze the emergence of modular production networks that has been documented in a number of global industry. For this purpose, an industry-equilibrium model has been set up in which the boundaries of the firm are endogenous in both the horizontal and vertical dimensions of production. As such, the model provides a better understanding of the various outsourcing strategies that are available to firms by distinguishing between three types of outsourcing. Under Ideal Outsourcing, "captured" intermediate good firms produce ideal components for final good firms. Under Standardized Outsourcing, "commodity" intermediate good firms produce standardized components for multiple final good producers and the burden of customizing the standardized components falls on the final good firm. Under Customized Outsourcing, "turn-key" intermediate good firms produce a base component for multiple final good firms and they face the burden of customization themselves.

The model demonstrates how the modularization of a product can induce a co-evolution of vertical outsourcing and horizontal consolidation in the intermediate good sector. If products are sufficiently modular and if intermediate good firms can exploit economies of scale, then it can become profitable for a vertically integrated firm to outsource component production to an intermediate good firm that uses a generic production process (Customized Outsourcing) or produces standardized inputs (Standardized Outsourcing) to multiple final good producers. As such, this paper links the emergence of modular production networks to the de facto standardization of inputs and production processes that has been taking place in high technology industries such as electronics, telecommunications, semi-conductors and automobiles (Schilling and Steensma, 2001; Sturgeon, 2002).

The model also provides new insights into Stigler's (1951) hypothesis that vertical disintegration should be the typical development in growing industries. In our model, an increase in industry demand induces a rise in the number of final good firms. This, on its part, leads to a decrease in equilibrium customization costs, thus inducing Standardized or Customized Outsourcing.

In summary, the model helps to better appreciate the impact of product modularity on an industry's organization of production in a world in which firms can choose from a multitude of organizational forms. Further research on this topic is needed. As is emphasized by the management 
literature, the degree of product modularity is not necessarily exogenous as is assumed in this paper, but is up to a certain extent endogenously determined by the management of the firm. Making the degree of product modularity a choice variable can thus provide novel and more complex insights on the role of modularity on the organization of production, and can ultimately lead to a general theory on the optimal degree of product modularity. 


\section{References}

[1] Abiru, M., Nahata, B., Raychaudhuri, S., Waterson, M., 1998. Equilibrium structure in a vertical oligopoly. Journal of Economic Behavior and Organization 37, 463-480.

[2] Antràs, P., 2003. Firms, contracts, and trade structure. Quarterly Journal of Economics 118, $1374-1418$.

[3] Antràs, P., Helpman, E., 2004. Global sourcing. Journal of Political Economy 112, 552-580.

[4] Baldwin, C.Y., Clark, K.B., 2000. Design Rules. MIT Press, Cambridge.

[5] Bresnahan, T., 1999. New modes of competition: implications for the future structure of the computer industry. In: Eisenach, J.A., Lenard, T.M. (Eds.), Competition, Innovation and the Microsoft Monopoly: Antitrust in the Digital Marketplace. Kluwer Academic Publishers, Boston.

[6] Dixit, A.K, Stiglitz, J.E., 1977, Monopolistic competition and optimum product diversity. American Economic Review 67(3), 297-308.

[7] Eaton, B.C., Schmitt, N., 1994. Flexible manufacturing and market structure. American Economic Review 84, 875-888.

[8] Economides, N., 1999. Competition, compatibility, and vertical integration in the computing industry. In: Eisenach, J.A., Lenard, T.M. (Eds.), Competition, Innovation and the Microsoft Monopoly: Antitrust in the Digital Marketplace. Kluwer Academic Publishers, Boston.

[9] Electronic Trend Publications, 2000. The Worldwide Contract Electronics Manufacturing Services Market, Eighth Edition: A Comprehensive Study On The Trends, Issues, and Leading Companies In The Worldwide Market For Contract Electronics Manufacturing Services. Electronic Trend Publications, San Jose.

[10] Feenstra, R.C., Huang, D.-S., Hamilton, G.G., 2003. A market-power based model of business groups. Journal of Economic Behavior and Organization 51, 459-485.

[11] Garud, R., Kumaraswamy, A., 1995. Technological and organizational designs to achieve economies of substitution. Strategic Management Journal 16, 93-109. 
[12] Grossman, S.J., Hart, O.D., 1986. Costs and benefits of ownership: a theory of vertical and lateral integration. Journal of Political Economy 94(4), 691-719.

[13] Grossman, G.M., Helpman, E., 2002. Integration versus outsourcing in industry equilibrium. Quarterly Journal of Economics 117, 85-120.

[14] Hart, O.D., Moore, J., 1990. Property rights and the nature of the firm. Journal of Political Economy 98, 1119-1158.

[15] Langlois R.N., 2002. Modularity in technology and organization. Journal of Economic Behavior and Organization 49, 19-37.

[16] Langlois, R.N., Steinmueller, W.E., 1999. The evolution of competitive advantage in the worldwide semiconductor industry, 1947-1996. In: Mowery, D.C., Nelson R.R. (Eds.), The Sources of Industrial Leadership. Cambridge University Press, New York, pp. 19-78.

[17] Li, F., Whalley, J., 2002. Deconstruction of the telecommunications industry: from value chains to value networks. Telecommunications Policy 26, 451-472.

[18] Sanchez, R., Mahoney, J.T. , 1996. Modularity, flexibility, and knowledge management in product and organization design. Strategic Management Journal 17, 63-76.

[19] Schilling, M.A., 2000. Towards a general modular systems theory and its application to interfirm product modularity. Academy of Management Review 25, 312-334.

[20] Schilling, M.A., Steensma, H.K., 2001. The use of modular organizational forms: an industrylevel analysis. Academy of Management Journal 44(6), 1149-1168.

[21] Spencer, B., 2005. International outsourcing and incomplete contracts. NBER Working Papers 11418.

[22] Spengler, J.J., 1950. Vertical integration and antitrust policy. Journal of Political Economy $58(4), 347-352$.

[23] Stigler, G., 1951. The division of labor is limited by the extent of the market. Journal of Political Economy 59(3), 185-193. 
[24] Sturgeon, T.J., 2002. Modular production networks: a new american model of industrial organization. Industrial and Corporate Change 11, 451-496.

[25] Sturgeon, T.J., Florida, R., 2000. Globalization and jobs in the automotive industry. MIT Industrial Performance Center Globalization Study Working Paper No. 01-003.

[27] Sturgeon, T.J., Lee, J.-R., 2001. Industry co-evolution and the rise of shared supply-base for electronics manufacturing. MIT Industrial Performance Center Globalization Study Working Paper No. 01-002.

[27] Sturgeon, T.J., Lester, R.K., 2003. The new global supply base: new challenges for local suppliers in East Asia. MIT Industrial Performance Center Globalization Study Working Paper No. 03-001.

[28] Ulrich, K.T., 1995. The role of product architecture in the manufacturing firm. Research Policy $24,419-440$.

[29] Van Assche, A., 2003. Modularity and the organization of international production. East-West Center Economics Series Working Paper No. 65. 